\title{
Reactive Oxygen Species and the Redox-Regulatory Network in Cold Stress Acclimation
}

\author{
Anna Dreyer ${ }^{D}$ and Karl-Josef Dietz * \\ Department of Biochemistry and Physiology of Plants, Faculty of Biology, University of Bielefeld, \\ 33615 Bielefeld, Germany; andreyer@techfak.uni-bielefeld.de \\ * Correspondence: karl-josef.dietz@uni-bielefeld.de; Tel.: +49-521-106-5589
}

Received: 31 October 2018; Accepted: 16 November 2018; Published: 21 November 2018

\begin{abstract}
Cold temperatures restrict plant growth, geographical extension of plant species, and agricultural practices. This review deals with cold stress above freezing temperatures often defined as chilling stress. It focuses on the redox regulatory network of the cell under cold temperature conditions. Reactive oxygen species (ROS) function as the final electron sink in this network which consists of redox input elements, transmitters, targets, and sensors. Following an introduction to the critical network components which include nicotinamide adenine dinucleotide phosphate (NADPH)-dependent thioredoxin reductases, thioredoxins, and peroxiredoxins, typical laboratory experiments for cold stress investigations will be described. Short term transcriptome and metabolome analyses allow for dissecting the early responses of network components and complement the vast data sets dealing with changes in the antioxidant system and ROS. This review gives examples of how such information may be integrated to advance our knowledge on the response and function of the redox regulatory network in cold stress acclimation. It will be exemplarily shown that targeting the redox network might be beneficial and supportive to improve cold stress acclimation and plant yield in cold climate.
\end{abstract}

Keywords: chilling stress; cold temperature; posttranslational modification; regulation; ROS; thiol redox network; thioredoxin

\section{Plant Response to Cold Temperature}

Biological systems are unavoidably affected by changes in ambient temperature. Such temperature effects particularly concern the temperature-dependent rates of spontaneous and enzyme-catalyzed chemical and physical reactions, the structural and molecular dynamics, and strength of molecular interactions. Each of these effects interferes with the state of metabolism and cellular signal processing. Many plants have evolved the capacity to adapt to low-temperature climates and develop locally distinct adaptive traits [1]. Thus, the response of photosynthetic metabolism to $4{ }^{\circ} \mathrm{C}$ varies not just between different species, but also between differently adapted populations. Oakley et al. [1] demonstrated this phenomenon with Arabidopsis from Italy and Sweden, and their crossing, by measuring the fast recovery of non-photochemical quenching after $2 \mathrm{~min}$ of darkening. The cold-acclimation response involves a profound reorganization of gene expression and posttranscriptional processes employing abscisic acid (ABA)-independent and dependent pathways [2]. The fraction of unsaturated fatty acid residues in cell membranes in particular linoleic acid (C18:2) increases at the expense of saturated lipids during chilling stress acclimation [3]. The fatty acid desaturation increases the fluidity of the membrane at a lower temperature and involves activation of fatty acid desaturases such as stearoyl-acyl carrier-protein desaturase (SAD) [4]. In addition, higher amounts and often different types of sugars and other osmolytes accumulate at low temperatures. Osmolyte accumulation is assumed to prepare for dehydration stress during freezing-induced water deficit [5]. In addition, the antioxidant defense is enhanced during cold stress acclimation [6,7]. In concert with reactive oxygen species (ROS) production, 
the antioxidant system controls the redox regulatory network of the cell. Our review focuses on this aspect of chilling stress acclimation and is intended to synthesize a broader perspective on redox network function and consequences.

\section{Cold Stress Experiments in the Laboratory}

Chilling stress occurs if non-primed plants or non-adapted plants, which are unable to be hardened, are exposed to cold temperatures significantly below growth temperature. Table 1 summarizes eight experiments of recent years. The genetic model plants Arabidopsis thaliana, Oryza sativa, and Sorghum bicolor, the genetic model Capsella bursa-pastoris, two Jatropha species with potential in biofuel production, and the medicinal plant Calendula officinalis were grown at $20-28^{\circ} \mathrm{C}$ during the light phase and $18-28^{\circ} \mathrm{C}$ during the night and then mostly transferred to $4{ }^{\circ} \mathrm{C}$, or 10,12 , and $15^{\circ} \mathrm{C}$, the latter for Capsella, rice, and soybean. Thus, the chosen temperature regimes covered down-shifts between 14 and $24{ }^{\circ} \mathrm{C}$ and were scrutinized for $30 \mathrm{~min}$ [8] to $14 \mathrm{~d}$ [6]. It is noteworthy that recovery from cold stress attracts increasing attention in Arabidopsis thaliana [6]. These authors recognized a positive relationship between the speed of recovery from $14 \mathrm{~d}$ chilling treatment and the strength of the plastid antioxidant system [6]. Thus, the Arabidopsis accessions N14, N13, Ms-0, and Kas-1, which grow under quite low temperatures in nature, displayed a weaker expression of some plastid antioxidant genes during the phase of $14 \mathrm{~d}$ cold treatment and simultaneously maintained a primed state after transfer to normal temperature. Maintenance of a primed state has an advantage if periods of chilling stress will return, but is disadvantageous for growth. Thus, maintenance of primed state has a trade-off for fitness at elevated temperatures [6]. 
Table 1. Experimental parameters used to explore chilling stress acclimation. See text for further description of the experiments.

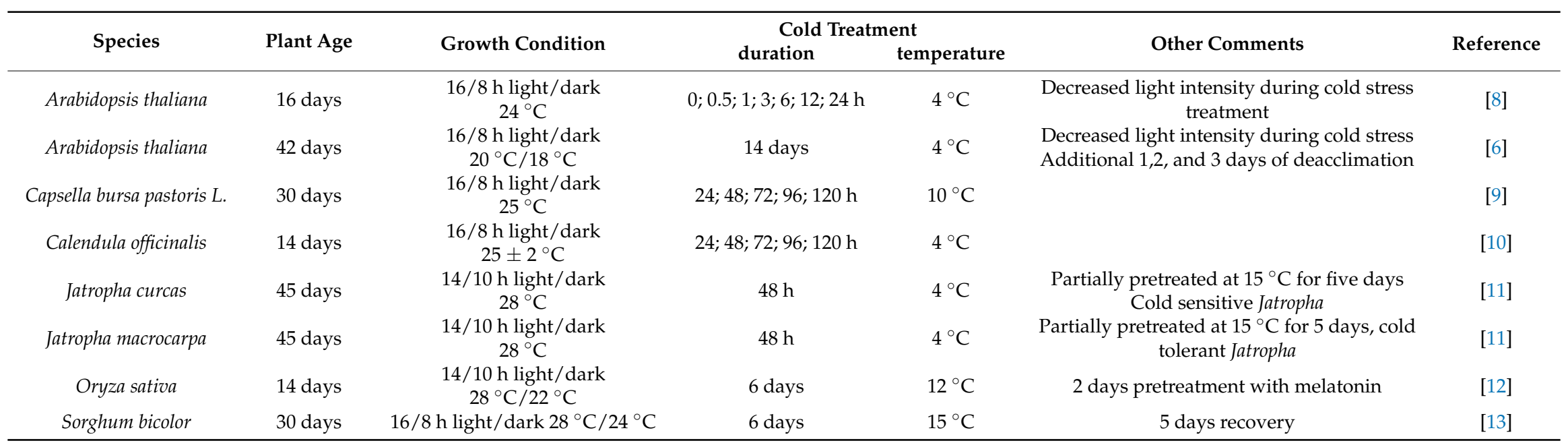




\section{Central Role of the Redox Regulatory Network in Stress Acclimation}

All cells express a regulatory network of thiol-containing proteins which integrates information from reductive metabolism and electron drainage from the network by ROS [14]. Targets of regulation by thiol oxidation are metabolic enzymes of various pathways, signal transduction elements, transcription and translation factors, and, thus, essentially all functional levels of the cell [15]. These target proteins are reduced by the concerted action of redox input elements and redox transmitters.

Redox input elements transfer electrons from metabolism to the redox transmitters. The nicotinamide adenine dinucleotide phosphate (NADPH)-dependent thioredoxin reductase A (NTRA) functions as such redox input element in the cytosol by transferring electrons from NADPH to thioredoxin (TRX). The same role is played by NTRB in the mitochondrion [16] and by NTRC in the chloroplast and other plastids [17]. NTRC is a variant which carries a TRX domain in addition to the NTR domain. An additional input element is the ferredoxin-dependent thioredoxin reductase (FTR) which transfers electrons from the photosynthetic electron transport chain (ETC) to TRX [18].

Decisive elements in redox regulation are TRX which constitutes large families in plants comprising proper TRX and TRX-like proteins. They function as redox transmitters. A genome-wide association study (GWAS) with soybean accessions grown at $28{ }^{\circ} \mathrm{C}$ and transferred to $15{ }^{\circ} \mathrm{C}$ for cold stress (Table 1) [13] discovered 143 genomic sites considered as promising for improving cold acclimation of soybean. Soybean is a C4 plant which is chilling sensitive. The study focused on photosynthetic performance during cold treatment and recovery. Among the identified genes of interest were two TRX genes, Sb03g004670 and Sb06g029490, which may contribute to the cold acclimation variation among the accessions [13]. These TRX-genes link cold stress to the regulation of the Calvin cycle $[13,19,20]$.

Thiol peroxidases have a very high affinity to $\mathrm{H}_{2} \mathrm{O}_{2}$, alkylhydroperoxides and peroxynitrite $\left(\mathrm{ONOO}^{-}\right)$. This group of enzymes comprises peroxiredoxins (PRX) and glutathione peroxidase-like proteins (GPX) and was suggested to control the spreading of peroxide signals in the cell. They act as redox sensors [21,22]. Their affinity and abundance support their function as primary reactants with peroxides. Recently, it was shown that the chloroplast 2-cysteine peroxiredoxin functions as thioredoxin oxidase and thereby co-controls the activation state of target proteins of redox regulation, such as malate dehydrogenase, phosphoribulokinase, and fructose-1,6-bisphosphatase [23]. Based on this study on chloroplast 2-cysteine peroxiredoxin it may be hypothesized that other thiol peroxidases play the same role in the redox regulatory network of plastids and other cell compartments.

The final electron acceptors of the network are peroxides which oxidize the redox sensors. Generator systems are the photosynthetic and respiratory ETC, substrate oxidases in peroxisomes and apoplast, and the NADPH oxidases in the plasma membrane [24]. Antioxidants counteract the accumulation of ROS and, thus, lower the electron drainage from the network (Figure 1). Oxidation of TRX by $\mathrm{O}_{2}$, direct oxidation of target proteins by peroxides or other mechanisms likely contribute to the oxidation of network components. But these mechanisms are poorly understood and may lack the specificity which is needed for tailored responses. 


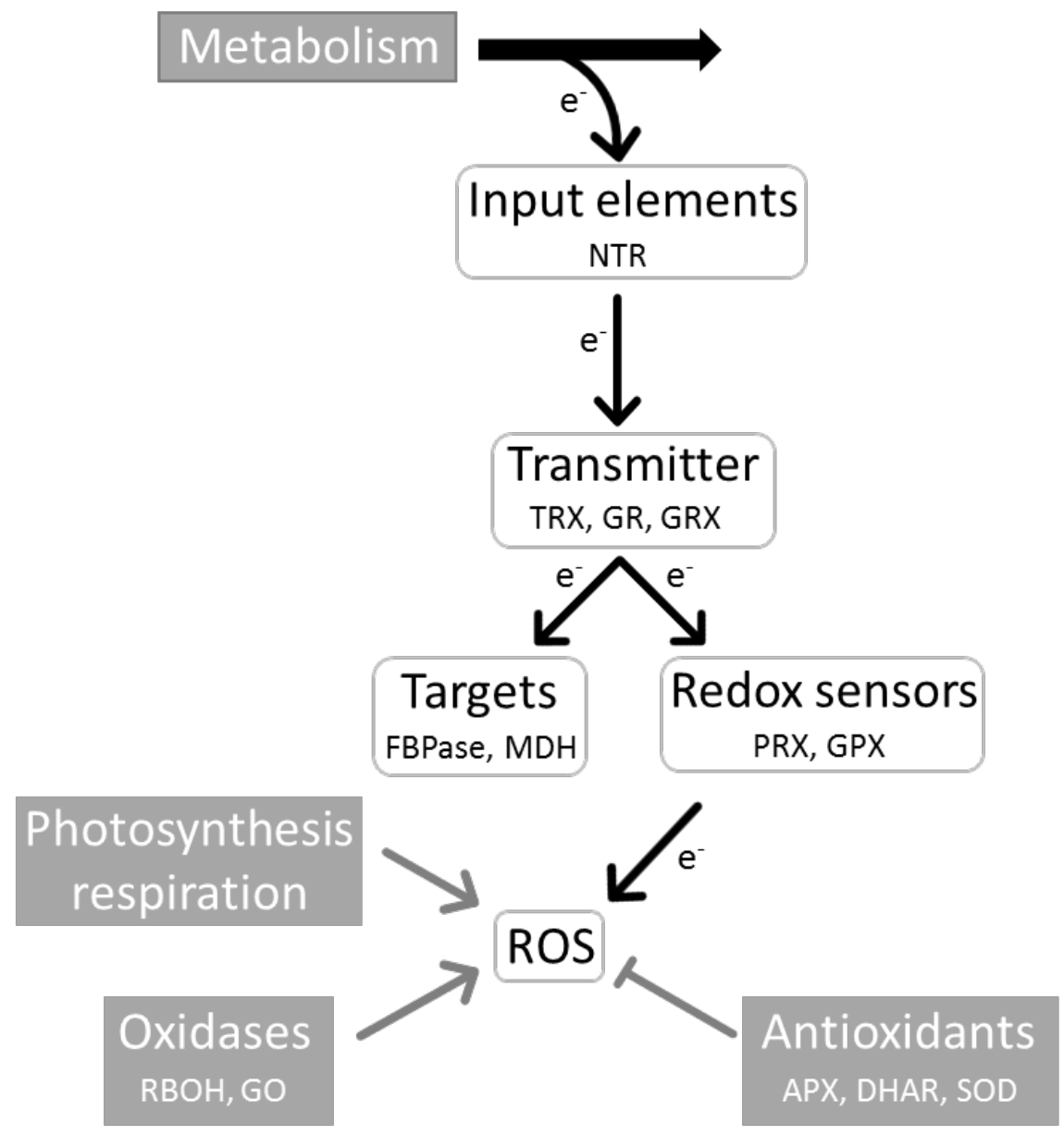

Figure 1. Basic structure of the redox regulatory network of the plant cell. Dependent on its state, metabolism feeds regulatory electrons via input elements (NTR: Nicotinamide adenine dinucleotide phosphate (NADPH)-dependent thioredoxin reductase) into the network. Redox transmitters (TRX: thioredoxin; GR: glutathione reductase, GRX: glutaredoxin) transfer electrons to regulated target proteins (FBPase: Fructose-1,6-bisphosphatase, MDH: malate dehydrogenase). Redox sensors (GPX: glutathione peroxidase (like), PRX: peroxiredoxin) also drain electrons from the transmitters in dependence on the ROS amount. The ROS amount is controlled by the activity of generator systems such as photosynthetic and respiratory electron transport chains and oxidases (RBOH: NADPH oxidase; GO: glycolate oxidase) and the decomposition of reactive oxygen species (ROS) by the antioxidant system (APX: ascorbate peroxidase, DHAR: dehydroascorbate reductase, SOD: superoxide dismutase). The proteins mentioned in the figure are typical representatives.

\section{Variability of Cold Response Between Species}

If the ambient temperatures drop significantly below growth temperature, an imbalance between photosynthetic light and dark reactions is established, and the photosynthetic electron transport chain releases more superoxide $\left(\mathrm{O}_{2}{ }^{-}\right)$by electron transfer to oxygen as alternative electron acceptor. $\mathrm{An}_{2}{ }^{-}$ increase is observed during chilling stress, e.g., in Cynodon dactylon [25].

Several studies indicate that increased superoxide dismutase (SOD) activity likely is related to chilling tolerance. SOD catalyzes the formation of hydrogen peroxide $\left(\mathrm{H}_{2} \mathrm{O}_{2}\right)$ and $\mathrm{H}_{2} \mathrm{O}$ from two superoxide molecules and two protons [26,27]. The response of SOD varies among species. Plants contain several SOD genes which often show species- and stress-specific expression patterns [28]. However, activity measurements usually cannot easily discriminate among the isoforms of $\mathrm{Mn}-, \mathrm{CuZn}-$ and Fe-SOD. The transcript amounts and activity of SOD increase during low-temperature treatment in Capsella bursa pastoris L. [9] and Calendula officinalis [10]. The SOD activity in Calendula officinalis 
rises less than the transcript amount pointing to posttranscriptional regulation of synthesis or higher protein degradation rates [10,29]. Likewise, the SOD activities of Phaseolus vulgaris [30], Cynodon dactylon [25], and Withania somnifera [31] only increase slightly upon exposure to low temperature. In the ecotype AGB025 of $W$. somnifera the SOD activity was even constant during the first three days of low-temperature treatment. In a converse manner, the ecotype AGB002, which is known to be more tolerant to chilling stress than AGB025, showed an increased enzyme activity [31].

Similar contrasting results were observed for two cell cultures derived from $O$. sativa subspecies Japonica cv. Nipponbare and Indica cv. 9311. The genotype Japonica known to be more adapted to chilling temperatures showed induced SOD activity after $24 \mathrm{~h}$ of low-temperature treatment, whereas the activity in Indica was constant during the $72 \mathrm{~h}$ of stress treatment [32,33]. The significant role of SOD is plausible if considering the role of ROS in addressing the thiol network as discussed above. $\mathrm{H}_{2} \mathrm{O}_{2}$ acts as an efficient electron sink while $\mathrm{O}_{2}^{-}$does not, but rather may cause damage, e.g., by peroxidation of lipids.

Unlike SOD, the catalase (CAT) activity in O. sativa Indica increased during the first $24 \mathrm{~h}$ of cold treatment but later on, returned to control level. CATs are localized in the peroxisomes and decompose $\mathrm{H}_{2} \mathrm{O}_{2}$ released from peroxisomal oxidases like glycolate oxidase with its role in photorespiration. CAT activity is important to minimize leakage of $\mathrm{H}_{2} \mathrm{O}_{2}$ from the peroxisome to the cytosol. The constitutively high SOD activity together with the transiently induced activity of CAT, could tune the accumulation of $\mathrm{H}_{2} \mathrm{O}_{2}$. In contrast to Indica, Japonica rice showed a relatively high, but constant, activity of CAT [32]. A similar increase of SOD and CAT activity was observed C. bursa-pastoris [9], Citrullus lanatus [34], and C. dactylon [25]. Therefore, SOD and CAT activity could play an important part during chilling stress, although some species like C. officinalis [10] and P. vulgaris [30] fail to increase the activity of these enzymes. The increased CAT is likely important to avoid accumulation of $\mathrm{H}_{2} \mathrm{O}_{2}$ if its production increases under cold due to imbalances and changes in metabolism.

The ascorbate-dependent Foyer-Halliwell-Asada cycle reduces $\mathrm{H}_{2} \mathrm{O}_{2}$ to water and is located in several subcellular compartments. This pathway relies on ascorbate peroxidases (APX) [27]. APX catalyzes the reduction of $\mathrm{H}_{2} \mathrm{O}_{2}$ to water by using ascorbate as electron donor, which results in the formation of dehydroascorbate (DHA). The produced DHA is recycled to ascorbate by dehydroascorbate reductase (DHAR) using glutathione as reductant (GSH). Liberated oxidized glutathione (GSSG) is regenerated by glutathione reductase (GR) using NADPH [26]. An ascorbate-independent water-water cycle for $\mathrm{H}_{2} \mathrm{O}_{2}$ reduction employs GPX and PRX which are found in plastids, mitochondria, and cytosol. The thiol peroxidases are part of the thiol network as described above. The oxidized thiol peroxidase reacts with an electron donor like TRX or glutathione with or without glutaredoxin (GRX) $[35,36]$.

The APX activity decreased in C. bursa pastoris during cold treatment of 1 to 5 days duration. This is quite unexpected in the light of high transcript levels observed during the first $24 \mathrm{~h}$ of low-temperature treatment [9] and could be due to posttranscriptional regulation [37,38] or APX inactivation by reaction with $\mathrm{H}_{2} \mathrm{O}_{2}$ in the absence of ascorbate [39]. APX inactivation could be a means to enable $\mathrm{H}_{2} \mathrm{O}_{2}$ accumulation for signaling. Quantification of APX protein levels would help to explain the weak correlation between transcript level and enzyme activity. To compensate for the instability of enzymes and to increase the antioxidant capacity, a constant supply of de novo synthesized proteins is needed [40]. This may explain why the transcript levels of the corresponding antioxidant enzymes usually increase under stress, e.g., in C. officinalis where both the transcript level and the activity of APX increased with prolonged time of low-temperature treatment [10]. APX activity also increased in cold-tolerant J. macrocarpa, whereas the APX activity decreased $>6$-fold in the cold-sensitive J. curcas [11]. The ascorbate-dependent water-water cycle is supported by stimulated ascorbate biosynthesis, strengthened glutathione homeostasis, enhanced sulphate reduction, and TRX pathway [41].

Apparently, different species reveal partly controversial responses of components of the antioxidant system. Considering the central role of redox homeostasis in cell function, this variation is 
surprising. Thus, the dependency of priming and resilience of the primed state on the strength of the chloroplast antioxidant system offers an important explanation for this variation [6].

\section{The Compartment-Specific Response of the Components of the Redox-Network to Cold in A. thaliana}

The enzymes of the redox-regulatory network are localized in different subcellular compartments of the cell (Figure 2A,C). Frequently more than one isoform of the redox elements is present in the different compartments. The three schemes assemble published transcript changes for the three subcellular compartments cytosol, chloroplast, and mitochondrion during a time course of $24 \mathrm{~h}$ cold treatment [8].

As outlined above, NADPH-dependent thioredoxin reductases (NTR) function as redox input elements and isoforms are present in each compartment. The relative transcript amounts of the cytosolic NTRA (Figure 2A), chloroplast NTRC (Figure 2B) and mitochondrial NTRB (Figure 2C) slightly decreased during the $24 \mathrm{~h}$ of low-temperature treatment. NTRC, which regenerates oxidized 2-Cys-PRX in an NADPH dependent manner [17,73], showed a similar decrease in expression as 2-Cys-PRXB (Figure 2B). The redox transmitters TRX and GRX transfer reducing equivalents to target proteins such as thiol peroxidases [74]. The downregulation of the h-type TRXs in the cytosol occurred in a peculiar time-dependent manner. TRX- $h 3$ was downregulated during the first $30 \mathrm{~min}, T R X-h 9$ after $1 \mathrm{~h}$, followed by $T R X-h 4, T R X-h 2$ and $T R X-h 1$ which only changed after $24 \mathrm{~h}$ of low-temperature treatment (Figure 2A).

Transcript levels of most of the redox sensors GPX and PRX were also downregulated during the low-temperature treatment. Small upregulation of cytosolic and mitochondrial GPX6 was an exception. In comparison to the downregulated transcript level of the PRXs after short-term cold stress, the transcript level of 2-Cys-PRXA, PRXQ, and PRXIIE increased after 14 days of cold stress treatment [6]. Transcripts for other enzymatic antioxidants like APX, monodehydroascorbate reductase (MDAR), dehydroascorbate reductase (DHAR) and SOD slightly decreased during the low-temperature treatment, whereas an increase of transcript level was observed for SAPX and MDAR after 14 days of chilling stress [6]. Although the APX and SOD transcript levels decreased during the first $24 \mathrm{~h}$ of cold treatment, the activity of both enzymes increased [75]. Later on after 4-8 days, APX and SOD activity reached the activity of untreated plants. This could be due to posttranscriptional regulation [76]. It would be interesting to scrutinize the weak relationship of transcript levels and enzyme activity by quantification of APX and SOD protein levels.

ROS are continuously generated in the photosynthetic and respiratory electron transport chain and during photorespiration $[77,78]$. Previously, it was estimated that about $30 \%$ of the electrons of the photosynthetic electron transport chain flow into ROS metabolism $[79,80]$. These figures were recently challenged by Driever and Baker [81] who only detected low amounts of ROS generated by the photosynthetic ETC. The authors proposed that this ROS releases feature signalling functions rather than serving as a major alternative electron acceptor. Furthermore, ROS are generated under normal conditions at low rates by NADPH oxidases (RBOH) [82]. The transcript amounts of $R B O H$ were downregulated, tentatively suggesting that the formation of ROS decreases at low temperatures. However, the activity and the protein level of these enzymes will have to be analyzed, since transcript levels poorly reflect the abundance or activity of their gene product [77].

In summary, it is striking that the main changes in transcript level only occurred after $24 \mathrm{~h}$ of low-temperature exposure. There were some exceptions: APX2 is considered as a sensitive marker of oxidative stress and is upregulated under conditions of excess excitation of the photosynthetic apparatus [83]. Here, APX2 was upregulated 2.4-fold after $30 \mathrm{~min}$ and maximally 5.6-fold after $6 \mathrm{~h}$ of cold treatment. Juszczak et al. [80] detected profound transcript changes after $14 \mathrm{~d}$ of cold treatment showing the persistence of metabolic disturbance at low temperatures. Thus, a global transcriptome analysis at later time points would be interesting to extend our analysis. 
A)

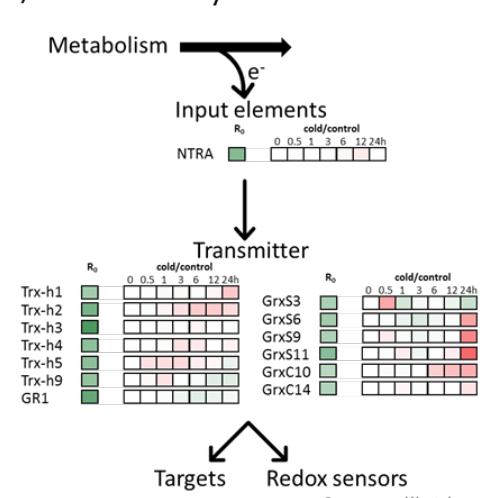

B)

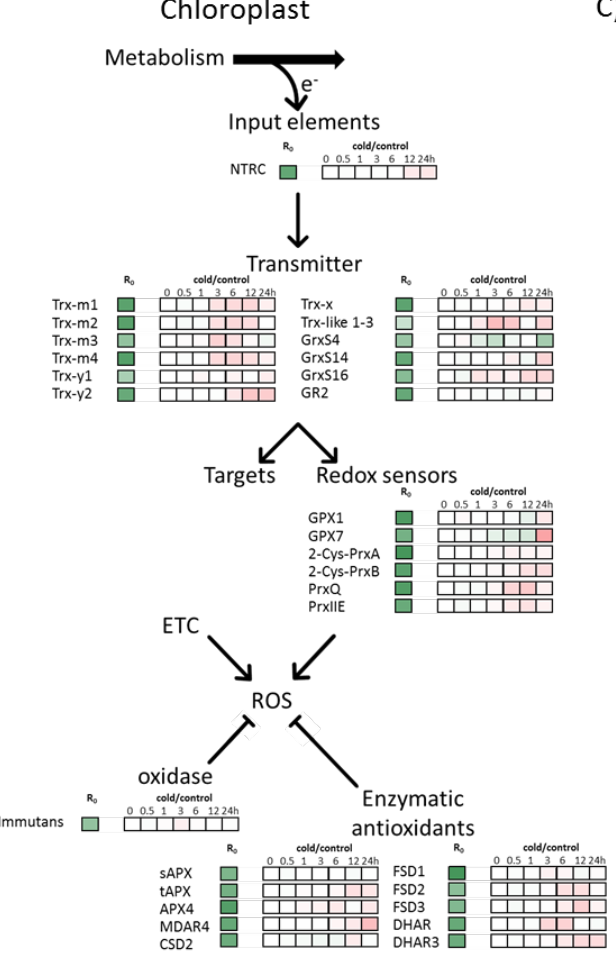

C)

Mitochondria

Metabolism
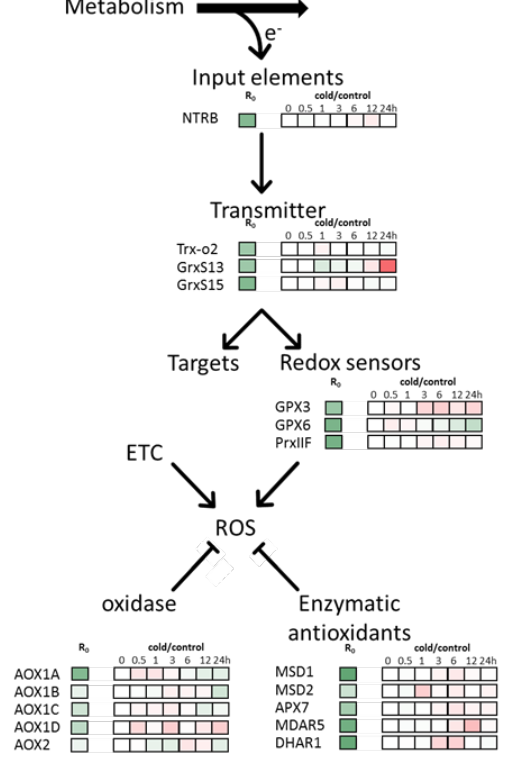

त्तायनान

Figure 2. Time-dependent change in transcript levels of the redox regulatory network in the cytosol (A), chloroplast (B), and mitochondrion (C) during chilling stress. Relative transcript levels in A. thaliana were obtained from the Gene Expression Omnibus (GEO) Database of National Center for Biotechnology Information (NCBI) (Accession GSE5620 for control conditions and GSE5621 for low temperature treated plants) [8]. R0 shows the transcription level normalized by the Affymetrix system. The other boxes indicate the transcript levels in cold treated plants compared to the control conditions at the depicted time point. A complete list with the precise $\log 2$-fold changes is provided in the supplement. AOX: Alternative oxidase; APX: Ascorbate peroxidase; CSD: Cu/Zn-superoxide dismutase; DHAR: Dehydroascorbate reductase; ETC: electron transport chain; FSD: Fe-superoxide dismutase; GR: Glutathione reductase; GRX: Glutaredoxin; GPX: Glutathione peroxidase; MDAR: Monodehydroascorbate reductase; NTR: NADPH-dependent thioredoxin reductase; PRX: Peroxiredoxin; Rboh: Respiratory burst oxidase homolog protein; TRX: Thioredoxin. The assignment of subcellular localization of the proteins listed in this figure was based on the references [42-72], see also Table S1. 
Furthermore, the cytosolic redox-regulatory network was stronger regulated than that of the chloroplast and mitochondria. The relatively small changes in transcript levels for chloroplast proteins of the network could be due to the setup in this particular experiment, where the light intensity was decreased from $150 \mu \mathrm{mol}$ photons $\mathrm{m}^{-2} \mathrm{~s}^{-1}$ during growth to just $60 \mu \mathrm{mol}$ photons $\mathrm{m}^{-2} \mathrm{~s}^{-1}$ during the low-temperature treatment [8]. The lowering of the incident photosynthetic active radiation probably minimizes the development of photoinhibition [84].

A. thaliana Col0 is sensitive to chilling stress and displays stunted growth, reduced metabolism and low biomass accumulation at low temperature [75]. Therefore, the transcriptional downregulation of the redox-regulatory network could participate in the chilling sensitivity of $A$. thaliana Col0.

\section{Improvement of Cold Tolerance by Modulating the Redox-Network}

Manipulation of the plant redox-network can enhance cold-stress tolerance [75,85-87]. Moon et al. [87] showed that overexpression of NTRC under control of the cauliflower mosaic 35S (CaMV35) promoter in A. thaliana enhances the tolerance to cold stress and freezing. These authors discussed NTRC and that it might affect the formation of secondary structures of mRNA at low temperatures to stimulate translation or protect nucleic acids against oxidative stress [87]. Since NTRC functions as a redox input element, it would be interesting to study the impact of NTRC overexpression on the redox network of the plastid including 2-Cys-PRX [17,82]. 2-Cys-PRXB, and NTRC showed similar decreases in transcript levels during short-term chilling stress (Figure 2B).

Improved cold tolerance was observed in tomato (Lycopersicon esculentum) overexpressing tAPX [85]. The tAPX overexpressing lines also revealed disturbed GSH/GSSG ratios which could be due to the impact of chloroplast redox state on GSH biosynthesis [88]. Furthermore, the high tAPX level in the transgenic tomatoes resulted in a decreased photoinhibition of photosystem I and II under chilling stress [85]. Increased NTRC and tAPX activity will shift the redox state of the chloroplast to a more reduced state, either by stimulated feeding of electrons into the network (NTRC) or decreasing the electron drainage to ROS.

Shafi et al. [75] transferred both $\mathrm{Cu} / \mathrm{Zn}-\mathrm{SOD}$ from Potentilla atrosanguinea and APX from Rheum australe (with high similarity to the peroxisomal APX gene of $A$. thaliana) under control of the 35SCaMV promoter into A. thaliana. Since P. atrosanguinea and $R$. australe grow in alpine climate, the authors hypothesized that their enzymatic system might be better adapted to stress than $A$. thaliana. Total soluble sugars and proline content increased in the transgenic line, which could help to maintain the membrane integrity. As a result, the electrolyte leakage was decreased under cold treatment at $4{ }^{\circ} \mathrm{C}$ compared to the wildtype (WT) [75]. The accumulation of cytosolic $\mathrm{O}_{2}{ }^{\bullet-}$ and $\mathrm{H}_{2} \mathrm{O}_{2}$ should be suppressed in these plants and, indeed, less ROS accumulated in the transgenic lines.

The overexpression of the cytosolic redox transmitter AtGRXS17 in tomato resulted in an enhanced chilling tolerance [86]. The activities of SOD, CAT, and heme peroxidases were higher in the AtGRXS17 overexpressing lines compared to the WT, while the transcript levels were almost identical. These results indicate that the enhanced chilling tolerance mediated by AtGRXS17 is associated with the activity and/or stability, rather than the transcript level, of the enzymes. Other reasons for the enhanced chilling tolerance could be due to the increase in total soluble sugars, the reduced accumulation of $\mathrm{H}_{2} \mathrm{O}_{2}$, and the reduced electrolyte leakage [85]. This particular GRX was previously shown to link redox and ROS homeostasis with auxin signaling and development [89].

These findings demonstrate that improved cold tolerance can be engineered in plants by manipulating elements of the redox-regulatory network and underline the significance of the network in chilling stress acclimation.

\section{Conclusions}

The state of the thiol redox regulatory network is under the control of electron input by metabolism and electron drainage to ROS. ROS amounts, in turn, are controlled by the activity of ROS generator systems and antioxidant defense systems. Conclusive evidence shows that redox network elements 
control important features of the cold acclimation and recovery program. This review focused on the thiol-disulfide network and its interaction with ROS and the antioxidant defense system. However, other players, such as classical hormones including abscisic acid, salicylic acid, and oxylipins, interfere with acclimation to chilling temperatures. More recently novel players were discovered to affect cold acclimation. They include $\gamma$-amino butyric acid and melatonin [90]. Keeping this in mind, a few conclusions can be drawn for future directions.

(1) Cold stress acclimation experiments often focus on leaves and photosynthetic metabolism. Response heterogeneity of different cell types has scarcely been addressed. Cell type-specific transcriptome, proteome, and metabolome analyses should reveal how other cell types respond to cold stress. But these approaches remain challenging and laborious.

(2) Only a few methods allow researchers to address subcellular compartments. Transcriptome data provide easy access due to the predicted and often proven subcellular localization of the encoded gene products. This approach is straightforward and was applied here to the redox regulatory network. It would be interesting to see this type of data processing more frequently. However, the transcript amount is poorly linked to protein amount and activity. For a full understanding, we need compartment-specific proteomics and enzyme activity tests.

(3) Metabolite-profiling of non-aqueous tissue fractions is another method which provides access to the major subcellular compartments. Non-aqueous fractions reflect the metabolic state of the compartments in vivo and are obtained from previously frozen and freeze-dried plant material like leaves [91]. This method was recently applied to cold-stress $A$. thaliana [92]. The latter study did not include metabolites with direct significance in the redox regulatory network.

(4) Subcellular and cellular specificity can be addressed by imaging technologies detecting specific physicochemical properties such as $\mathrm{Ca}^{2+}$-activity, specific compounds or the redox state of the glutathione system by using roGFP coupled to GRX [93]. The roGFP:GRX sensor can be targeted to different cell compartments and should be used to explore the glutathione redox state in dependence on cold stress intensity and duration.

(5) To describe the state of the redox network in subcellular compartments, mathematical modeling and simulation combined with redox-proteomics for validation will be required. A pioneering modeling study presented a simulation of the fluxes through the ascorbate-dependent water-water cycle [94] and most recently, the thioredoxin oxidase-dependent inactivation of chloroplast enzymes was simulated [23]. Conceptually, cold stress appears to be an interesting target for this kind of simulation and prediction.

(6) The question of acclimation and damage during the cold period is certainly of significant interest. However, the costs of priming and the speed of recovery likely play a major role when it comes to fitness and competitiveness. Thus, the report by Juszczak et al. [6] deserves attention as it provides clues on the advantages and disadvantages of expressing a strong antioxidant system.

Supplementary Materials: The following are available online at http:/ / www.mdpi.com/2076-3921/7/11/169/s1, Table S1: Time-dependent changes in transcript levels of the redox network components.

Author Contributions: A.D. conceptualization, formal analysis, writing-original draft preparation, K.-J.D.; conceptualization, writing-Original draft preparation, project administration, funding acquisition.

Funding: The own research was funded by the Deutsche Foschungsgemeinschaft (Di 346, SPP1710).

Conflicts of Interest: The authors declare no conflict of interest. 


\section{References}

1. Oakley, C.G.; Savage, L.; Lotz, S.; Larson, G.R.; Thomashow, M.F.; Kramer, D.M.; Schemske, D.W. Genetic basis of photosynthetic responses to cold in two locally adapted populations of Arabidopsis thaliana. J. Exp. Bot. 2018, 69, 699-709. [CrossRef] [PubMed]

2. Thomashow, M.F. PLANT COLD ACCLIMATION: Freezing Tolerance Genes and Regulatory Mechanisms. Ann. Rev. Plant Physiol. Plant Mol. Biol. 1999, 50, 571-599. [CrossRef] [PubMed]

3. Hayward, S.A.L.; Murray, P.A.; Gracey, A.Y.; Cossins, A.R. Beyond the Lipid Hypothesis. In Molecular Aspects of the Stress Response: Chaperones, Membranes and Networks; Csermely, P., Vígh, L., Eds.; Springer: New York, NY, USA, 2007; pp. 132-142.

4. $\quad$ Li, F.; Bian, C.S.; Xu, J.F.; Pang, W.F.; Liu, J.; Duan, S.G.; Lei, Z.-G.; Jiwan, P.; Jin, L.-P. Cloning and functional characterization of SAD genes in potato. PloS ONE 2015, 10, e0122036. [CrossRef] [PubMed]

5. Li, Z.-G.; Yuan, L.-X.; Wang, Q.-L.; Ding, Z.-L.; Dong, C.-Y. Combined action of antioxidant defense system and osmolytes in chilling shock-induced chilling tolerance in Jatropha curcas seedlings. Acta Physiol. Plantarum 2013, 35, 2127-2136. [CrossRef]

6. Juszczak, I.; Cvetkovic, J.; Zuther, E.; Hincha, D.K.; Baier, M. Natural Variation of Cold Deacclimation Correlates with Variation of Cold-Acclimation of the Plastid Antioxidant System in Arabidopsis thaliana Accessions. Front. Plant Sci. 2016, 7, 305. [CrossRef] [PubMed]

7. Li, X.; Cai, J.; Liu, F.; Dai, T.; Cao, W.; Jiang, D. Cold priming drives the sub-cellular antioxidant systems to protect photosynthetic electron transport against subsequent low temperature stress in winter wheat. Plant Physiol. Biochem. PРВ 2014, 82, 34-43. [CrossRef] [PubMed]

8. Kilian, J.; Whitehead, D.; Horak, J.; Wanke, D.; Weinl, S.; Batistic, O.; D’Angelo, C.; Bornberg-Bauer, E.; Kudla, J.; Harter, K. The AtGenExpress global stress expression data set: Protocols, evaluation and model data analysis of UV-B light, drought and cold stress responses. Plant J. 2007, 50, 347-363. [CrossRef] [PubMed]

9. Wani, M.A.; Jan, N.; Qazi, H.A.; Andrabi, K.I.; John, R. Cold stress induces biochemical changes, fatty acid profile, antioxidant system and gene expression in Capsella bursa pastoris L. Acta Physiol. Plantarum 2018, 40, 167. [CrossRef]

10. Jan, N.; Majeed, U.; Andrabi, K.I.; John, R. Cold stress modulates osmolytes and antioxidant system in Calendula officinalis. Acta Physiol. Plantarum 2018, 40, 73. [CrossRef]

11. Spanò, C.; Bottega, S.; Ruffini Castiglione, M.; Pedranzani, H.E. Antioxidant response to cold stress in two oil plants of the genus Jatropha. Plant Soil Environ. 2017, 63, 271-276. [CrossRef]

12. Han, Q.-H.; Huang, B.; Ding, C.-B.; Zhang, Z.-W.; Chen, Y.-E.; Hu, C.; Zhou, L.-J.; Huang, Y.; Liao, J.-Q.; Yuan, S.; et al. Effects of Melatonin on Anti-oxidative Systems and Photosystem II in Cold-Stressed Rice Seedlings. Front. Plant Sci. 2017, 8, 785. [CrossRef] [PubMed]

13. Ortiz, D.; Hu, J.; Salas Fernandez, M.G. Genetic architecture of photosynthesis in Sorghum bicolor under non-stress and cold stress conditions. J. Exp. Bot. 2017, 68, 4545-4557. [CrossRef] [PubMed]

14. Dietz, K.-J. Redox signal integration: From stimulus to networks and genes. Physiol. Plant 2008, 133, 459-468. [CrossRef] [PubMed]

15. Buchanan, B.B. The Path to Thioredoxin and Redox Regulation in Chloroplasts. Ann. Rev. Plant Biol. 2016, 67, 1-24. [CrossRef] [PubMed]

16. Reichheld, J.-P.; Khafif, M.; Riondet, C.; Droux, M.; Bonnard, G.; Meyer, Y. Inactivation of thioredoxin reductases reveals a complex interplay between thioredoxin and glutathione pathways in Arabidopsis development. Plant Cell 2007, 19, 1851-1865. [CrossRef] [PubMed]

17. Serrato, A.J.; Pérez-Ruiz, J.M.; Spínola, M.C.; Cejudo, F.J. A novel NADPH thioredoxin reductase, localized in the chloroplast, which deficiency causes hypersensitivity to abiotic stress in Arabidopsis thaliana. J. Biol. Chem. 2004, 279, 43821-43827. [CrossRef] [PubMed]

18. Keryer, E.; Collin, V.; Lavergne, D.; Lemaire, S.; Issakidis-Bourguet, E. Characterization of Arabidopsis Mutants for the Variable Subunit of Ferredoxin:thioredoxin Reductase. Photosynthes. Res. 2004, 79, 265-274. [CrossRef] [PubMed]

19. Okegawa, Y.; Motohashi, K. Chloroplastic thioredoxin $\mathrm{m}$ functions as a major regulator of Calvin cycle enzymes during photosynthesis in vivo. Plant J. 2015, 84, 900-913. [CrossRef] [PubMed]

20. Raines, C.A. The Calvin cycle revisited. Photosynthes. Res. 2003, 75, 1-10. [CrossRef] [PubMed] 
21. Flohe, L. The impact of thiol peroxidases on redox regulation. Free Rad. Res. 2016, 50, 126-142. [CrossRef] [PubMed]

22. Dietz, K.-J. Thiol-Based Peroxidases and Ascorbate Peroxidases: Why Plants Rely on Multiple Peroxidase Systems in the Photosynthesizing Chloroplast? Mol. Cells 2016, 39, 20-25. [CrossRef] [PubMed]

23. Vaseghi, M.-J.; Chibani, K.; Telman, W.; Liebthal, M.F.; Gerken, M.; Schnitzer, H.; Mueller, S.M.; Dietz, K.-J. The chloroplast 2-cysteine peroxiredoxin functions as thioredoxin oxidase in redox regulation of chloroplast metabolism. eLife 2018, 7. [CrossRef] [PubMed]

24. Hossain, M.S.; Dietz, K.-J. Tuning of Redox Regulatory Mechanisms, Reactive Oxygen Species and Redox Homeostasis under Salinity Stress. Front. Plant Sci. 2016, 7, 548. [CrossRef] [PubMed]

25. Shi, H.; Ye, T.; Zhong, B.; Liu, X.; Chan, Z. Comparative proteomic and metabolomic analyses reveal mechanisms of improved cold stress tolerance in bermudagrass (Cynodon dactylon (L.) Pers.) by exogenous calcium. J. Integrat. Plant Biol. 2014, 56, 1064-1079. [CrossRef] [PubMed]

26. Asada, K. THE WATER-WATER CYCLE IN CHLOROPLASTS: Scavenging of Active Oxygens and Dissipation of Excess Photons. Ann. Rev. Plant Physiol. Plant Mol. Biol. 1999, 50, 601-639. [CrossRef] [PubMed]

27. Foyer, C.H.; Shigeoka, S. Understanding oxidative stress and antioxidant functions to enhance photosynthesis. Plant Physiol. 2011, 155, 93-100. [CrossRef] [PubMed]

28. Hossain, M.S.; ElSayed, A.I.; Moore, M.; Dietz, K.-J. Redox and Reactive Oxygen Species Network in Acclimation for Salinity Tolerance in Sugar Beet. J. Exp. Bot. 2017, 68, 1283-1298. [CrossRef] [PubMed]

29. Yan, S.-P.; Zhang, Q.-Y.; Tang, Z.-C.; Su, W.-A.; Sun, W.-N. Comparative proteomic analysis provides new insights into chilling stress responses in rice. Mol. Cell. Proteom. MCP 2006, 5, 484-496. [CrossRef] [PubMed]

30. Soliman, M.H.; Alayafi, A.A.M.; El Kelish, A.A.; Abu-Elsaoud, A.M. Acetylsalicylic acid enhance tolerance of Phaseolus vulgaris L. to chilling stress, improving photosynthesis, antioxidants and expression of cold stress responsive genes. Botan. Stud. 2018, 59, 6. [CrossRef] [PubMed]

31. Mir, B.A.; Mir, S.A.; Khazir, J.; Tonfack, L.B.; Cowan, D.A.; Vyas, D.; Koul, S. Cold stress affects antioxidative response and accumulation of medicinally important withanolides in Withania somnifera (L.) Dunal. Ind. Crops Prod. 2015, 74, 1008-1016. [CrossRef]

32. Wang, X.; Fang, G.; Li, Y.; Ding, M.; Gong, H.; Li, Y. Differential antioxidant responses to cold stress in cell suspension cultures of two subspecies of rice. Plant Cell Tiss Organ Cult 2013, 113, 353-361. [CrossRef]

33. Glaszmann, J.C.; Kaw, R.N.; Khush, G.S. Genetic divergence among cold tolerant rices (Oryza sativa L.). Euphytica 1990, 45, 95-104. [CrossRef]

34. Cheng, F.; Lu, J.; Gao, M.; Shi, K.; Kong, Q.; Huang, Y.; Bie, Z. Redox Signaling and CBF-Responsive Pathway Are Involved in Salicylic Acid-Improved Photosynthesis and Growth under Chilling Stress in Watermelon. Front. Plant Sci. 2016, 7, 1519. [CrossRef] [PubMed]

35. Dietz, K.J.; Horling, F.; Konig, J.; Baier, M. The function of the chloroplast 2-cysteine peroxiredoxin in peroxide detoxification and its regulation. J. Exp. Bot. 2002, 53, 1321-1329.

36. Dietz, K.-J. Peroxiredoxins in plants and cyanobacteria. Antioxid. Redox Signal. 2011, 15, 1129-1159. [CrossRef] [PubMed]

37. Dat, J.; Vandenabeele, S.; Vranova, E.; van Montagu, M.; Inze, D.; van Breusegem, F. Dual action of the active oxygen species during plant stress responses. Cell. Mol. Life Sci. 2000, 57, 779-795. [CrossRef] [PubMed]

38. Cavalcanti, F.R.; Oliveira, J.T.A.; Martins-Miranda, A.S.; Viégas, R.A.; Silveira, J.A.G. Superoxide dismutase, catalase and peroxidase activities do not confer protection against oxidative damage in salt-stressed cowpea leaves. New Phytol. 2004, 163, 563-571. [CrossRef]

39. Baier, M.; Pitsch, N.T.; Mellenthin, M.; Guo, W. Regulation of Genes Encoding Chloroplast Antioxidant Enzymes in Comparison to Regulation of the Extra-plastidic Antioxidant Defense System. In Ascorbate-Glutathione Pathway and Stress Tolerance in Plants; Anjum, N.A., Chan, M.-T., Umar, S., Eds.; Springer Netherlands: Dordrecht, The Netherland, 2010.

40. Muthuramalingam, M.; Matros, A.; Scheibe, R.; Mock, H.-P.; Dietz, K.-J. The hydrogen peroxide-sensitive proteome of the chloroplast in vitro and in vivo. Front Plant Sci. 2013, 4, 54. [CrossRef] [PubMed]

41. Koç, I.; Yuksel, I.; Caetano-Anollés, G. Metabolite-Centric Reporter Pathway and Tripartite Network Analysis of Arabidopsis Under Cold Stress. Front Bioeng. Biotechnol. 2018, 6, 121. [CrossRef] [PubMed] 
42. Kliebenstein, D.J.; Monde, R.-A.; Last, R.L. Superoxide Dismutase in Arabidopsis: An Eclectic Enzyme Family with Disparate Regulation and Protein Localization. Plant Physiol. 1998, 118, 637-650. [CrossRef] [PubMed]

43. Huang, C.-H.; Kuo, W.-Y.; Weiss, C.; Jinn, T.-L. Copper Chaperone-Dependent and -Independent Activation of Three Copper-Zinc Superoxide Dismutase Homologs Localized in Different Cellular Compartments in Arabidopsis. Plant Physiol. 2012, 158, 737-746. [CrossRef] [PubMed]

44. Panchuk, I.I.; Volkov, R.A.; Schöffl, F. Heat Stress- and Heat Shock Transcription Factor-Dependent Expression and Activity of Ascorbate Peroxidase in Arabidopsis. Plant Physiol. 2002, 129, 838-853. [CrossRef] [PubMed]

45. Mittler, R.; Poulos, T.L. Ascorbate Peroxidase. In Antioxidants and Reactive Oxygen Species in Plants; Wiley-Blackwell: Hoboken, NJ, USA, 2007; pp. 87-100.

46. Lisenbee, C.S.; Lingard, M.J.; Trelease, R.N. Arabidopsis peroxisomes possess functionally redundant membrane and matrix isoforms of monodehydroascorbate reductase. Plant J. 2005, 43, 900-914. [CrossRef] [PubMed]

47. Obara, K.; Sumi, K.; Fukuda, H. The Use of Multiple Transcription Starts Causes the Dual Targeting of Arabidopsis Putative Monodehydroascorbate Reductase to Both Mitochondria and Chloroplasts. Plant Cell Physiol. 2002, 43, 697-705. [CrossRef] [PubMed]

48. Chew, O.; Whelan, J.; Millar, A.H. Molecular definition of the ascorbate-glutathione cycle in Arabidopsis mitochondria reveals dual targeting of antioxidant defenses in plants. J. Biol. Chem. 2003, 278, 46869-46877. [CrossRef] [PubMed]

49. Reumann, S.; Quan, S.; Aung, K.; Yang, P.; Manandhar-Shrestha, K.; Holbrook, D.; Linka, N.; Switzenberg, R.; Wilkerson, C.G.; Weber, A.P.M.; et al. In-depth proteome analysis of Arabidopsis leaf peroxisomes combined with in vivo subcellular targeting verification indicates novel metabolic and regulatory functions of peroxisomes. Plant Physiol. 2009, 150, 125-143. [CrossRef] [PubMed]

50. Dixon, D.P.; Davis, B.G.; Edwards, R. Functional divergence in the glutathione transferase superfamily in plants. Identification of two classes with putative functions in redox homeostasis in Arabidopsis thaliana. J. biol. chem. 2002, 277, 30859-30869. [CrossRef] [PubMed]

51. Trivedi, D.K.; Gill, S.S.; Yadav, S.; Tuteja, N. Genome-wide analysis of glutathione reductase (GR) genes from rice and Arabidopsis. Plant Signal. Behav. 2012, 8, e23021. [CrossRef] [PubMed]

52. Mhamdi, A.; Queval, G.; Chaouch, S.; Vanderauwera, S.; van Breusegem, F.; Noctor, G. Catalase function in plants: A focus on Arabidopsis mutants as stress-mimic models. J. Exp. Bot. 2010, 61, 4197-4220. [CrossRef] [PubMed]

53. Milla, M.A.R.; Maurer, A.; Huete, A.R.; Gustafson, J.P. Glutathione peroxidase genes in Arabidopsis are ubiquitous and regulated by abiotic stresses through diverse signaling pathways. Plant J. 2003, 36, 602-615. [CrossRef]

54. Sagi, M.; Fluhr, R. Superoxide Production by Plant Homologues of the gp91phox NADPH Oxidase. Modulation of Activity by Calcium and by Tobacco Mosaic Virus Infection. Plant Physiol. 2001, 126, 1281-1290. [CrossRef] [PubMed]

55. Heazlewood, J.L.; Tonti-Filippini, J.S.; Gout, A.M.; Day, D.A.; Whelan, J.; Millar, A.H. Experimental analysis of the Arabidopsis mitochondrial proteome highlights signaling and regulatory components, provides assessment of targeting prediction programs, and indicates plant-specific mitochondrial proteins. Plant Cell Online 2004, 16, 241-256. [CrossRef] [PubMed]

56. Konert, G.; Trotta, A.; Kouvonen, P.; Rahikainen, M.; Durian, G.; Blokhina, O.; Fagerstedt, K.; Muth, D.; Corthals, G.L.; Kangasjärvi, S. Protein phosphatase 2A (PP2A) regulatory subunit $\mathrm{B}^{\prime} \gamma$ interacts with cytoplasmic ACONITASE 3 and modulates the abundance of AOX1A and AOX1D in Arabidopsis thaliana. New Phytol. 2014, 205, 1250-1263. [CrossRef] [PubMed]

57. Saisho, D.; Nakazono, M.; Lee, K.-H.; Tsutsumi, N.; Akita, S.; Hirai, A. The gene for alternative oxidase-2 (AOX2) from Arabidopsis thaliana consists of five exons unlike other AOX genes and is transcribed at an early stage during germination. Genes Genet. Syst. 2001, 76, 89-97. [CrossRef]

58. Lennon, A.M.; Prommeenate, P.; Nixon, P.J. Location, expression and orientation of the putative chlororespiratory enzymes, Ndh and IMMUTANS, in higher-plant plastids. Planta 2003, 218, 254-260. [CrossRef] [PubMed] 
59. Haslekås, C.; Viken, M.K.; Grini, P.E.; Nygaard, V.; Nordgard, S.H.; Meza, T.J.; Aalen, R.B. Seed 1-Cysteine Peroxiredoxin Antioxidants Are Not Involved in Dormancy, But Contribute to Inhibition of Germination during Stress. Plant Physiol. 2003, 133, 1148-1157. [CrossRef] [PubMed]

60. König, J.; Baier, M.; Horling, F.; Kahmann, U.; Harris, G.; Schürmann, P.; Dietz, K.-J. The plant-specific function of 2-Cys peroxiredoxin-mediated detoxification of peroxides in the redox-hierarchy of photosynthetic electron flux. Proc. Natl. Acad. Sci. USA 2002, 99, 5738-5743. [CrossRef] [PubMed]

61. Lamkemeyer, P.; Laxa, M.; Collin, V.; Li, W.; Finkemeier, I.; Schöttler, M.A.; Holtkamp, V.; Tognetti, V.B.; Issakidis-Bourguet, E.; Kandlbinder, A.; et al. Peroxiredoxin Q of Arabidopsis thaliana is attached to the thylakoids and functions in context of photosynthesis ${ }^{\dagger}$. Plant J. 2006, 45, 968-981. [CrossRef] [PubMed]

62. Bréhélin, C.; Meyer, E.H.; de Souris, J.-P.; Bonnard, G.; Meyer, Y. Resemblance and Dissemblance of Arabidopsis Type II Peroxiredoxins: Similar Sequences for Divergent Gene Expression, Protein Localization, and Activity. Plant Physiol. 2003, 132, 2045-2057. [CrossRef] [PubMed]

63. Finkemeier, I.; Goodman, M.; Lamkemeyer, P.; Kandlbinder, A.; Sweetlove, L.J.; Dietz, K.-J. The mitochondrial type II peroxiredoxin $\mathrm{F}$ is essential for redox homeostasis and root growth of Arabidopsis thaliana under stress. J. Biol. Chem. 2005, 280, 12168-12180. [CrossRef] [PubMed]

64. Meyer, Y.; Siala, W.; Bashandy, T.; Riondet, C.; Vignols, F.; Reichheld, J.P. Glutaredoxins and thioredoxins in plants. Biochim. Biophys. Acta 2008, 1783, 589-600. [CrossRef] [PubMed]

65. Reichheld, J.-P.; Meyer, E.; Khafif, M.; Bonnard, G.; Meyer, Y. AtNTRB is the major mitochondrial thioredoxin reductase in Arabidopsis thaliana. FEBS Lett. 2005, 579, 337-342. [CrossRef] [PubMed]

66. Dangoor, I.; Peled-Zehavi, H.; Levitan, A.; Pasand, O.; Danon, A. A small family of chloroplast atypical thioredoxins. Plant Physiol. 2009, 149, 1240-1250. [CrossRef] [PubMed]

67. Lemaire, S.D. The Glutaredoxin Family in Oxygenic Photosynthetic Organisms. Photosynthes. Res. 2004, 79, 305-318. [CrossRef] [PubMed]

68. Cheng, N.-H. AtGRX4, an Arabidopsis chloroplastic monothiol glutaredoxin, is able to suppress yeast grx5 mutant phenotypes and respond to oxidative stress. FEBS Lett. 2008, 582, 848-854. [CrossRef] [PubMed]

69. Cheng, N.-H.; Liu, J.-Z.; Brock, A.; Nelson, R.S.; Hirschi, K.D. AtGRXcp, an Arabidopsis chloroplastic glutaredoxin, is critical for protection against protein oxidative damage. J. Biol. Chem. 2006, 281, 26280-26288. [CrossRef] [PubMed]

70. Liu, X.; Liu, S.; Feng, Y.; Liu, J.-Z.; Chen, Y.; Pham, K.; Deng, H.; Hirschi, K.D.; Wang, X.; Cheng, N. Structural insights into the N-terminal GIY-YIG endonuclease activity of Arabidopsis glutaredoxin AtGRXS16 in chloroplasts. Proc. Natl. Acad. Sci. USA 2013, 110, 9565-9570. [CrossRef] [PubMed]

71. Li, S.; Lauri, A.; Ziemann, M.; Busch, A.; Bhave, M.; Zachgo, S. Nuclear activity of ROXY1, a glutaredoxin interacting with TGA factors, is required for petal development in Arabidopsis thaliana. Plant Cell Online 2009, 21, 429-441. [CrossRef] [PubMed]

72. Murmu, J.; Bush, M.J.; DeLong, C.; Li, S.; Xu, M.; Khan, M.; Malcolmson, C.; Fobert, P.R.; Zachgo, S.; Hepworth, S.R. Arabidopsis basic leucine-zipper transcription factors TGA9 and TGA10 interact with floral glutaredoxins ROXY1 and ROXY2 and are redundantly required for anther development. Plant Physiol. 2010, 154, 1492-1504. [CrossRef] [PubMed]

73. König, J.; Muthuramalingam, M.; Dietz, K.-J. Mechanisms and dynamics in the thiol/disulfide redox regulatory network: Transmitters, sensors and targets. Curr. Opin. Plant Biol. 2012, 15, 261-268. [CrossRef] [PubMed]

74. Meyer, Y.; Buchanan, B.B.; Vignols, F.; Reichheld, J.-P. Thioredoxins and Glutaredoxins: Unifying Elements in Redox Biology. Ann. Rev. Genet. 2009, 43, 335-367. [CrossRef] [PubMed]

75. Shafi, A.; Dogra, V.; Gill, T.; Ahuja, P.S.; Sreenivasulu, Y. Simultaneous over-expression of PaSOD and RaAPX in transgenic Arabidopsis thaliana confers cold stress tolerance through increase in vascular lignifications. PloS one 2014, 9, e110302. [CrossRef] [PubMed]

76. Schwanhäusser, B.; Busse, D.; Li, N.; Dittmar, G.; Schuchhardt, J.; Wolf, J.; Chen, W.; Selbach, M. Global quantification of mammalian gene expression control. Nature 2011, 473, 337. [CrossRef] [PubMed]

77. Mittler, R.; Vanderauwera, S.; Gollery, M.; van Breusegem, F. Reactive oxygen gene network of plants. Trends Plant Sci. 2004, 9, 490-498. [CrossRef] [PubMed]

78. Apel, K.; Hirt, H. REACTIVE OXYGEN SPECIES: Metabolism, Oxidative Stress, and Signal Transduction. Ann. Rev. Plant Biol. 2004, 55, 373-399. [CrossRef] [PubMed] 
79. Miyake, C.; Michihata, F.; Asada, K. Scavenging of Hydrogen Peroxide in Prokaryotic and Eukaryotic Algae: Acquisition of Ascorbate Peroxidase during the Evolution of Cyanobacteria. Plant Cell Physiol. 1991, 32, 33-43. [CrossRef]

80. Juszczak, I.; Rudnik, R.; Pietzenuk, B.; Baier, M. Natural genetic variation in the expression regulation of the chloroplast antioxidant system among Arabidopsis thaliana accessions. Physiol. Plantarum 2012, 146, 53-70. [CrossRef] [PubMed]

81. Driever, S.M.; Baker, N.R. The water-water cycle in leaves is not a major alternative electron sink for dissipation of excess excitation energy when $\mathrm{CO}(2)$ assimilation is restricted. Plant Cell Environ. 2011, 34, 837-846. [CrossRef] [PubMed]

82. Liebthal, M.; Maynard, D.; Dietz, K.-J. Peroxiredoxins and Redox Signaling in Plants. Antioxid. Redox Signal. 2018, 28, 609-624. [CrossRef] [PubMed]

83. Karpinski, S.; Reynolds, H.; Karpinska, B.; Wingsle, G.; Creissen, G.; Mullineaux, P. Systemic Signaling and Acclimation in Response to Excess Excitation Energy in Arabidopsis. Science 1999, 284, 654-657. [CrossRef] [PubMed]

84. Krause, G.H.; Somersalo, S.; Osmond, C.B.; Briantais, J.-M.; Schreiber, U. Fluorescence as a Tool in Photosynthesis Research: Application in Studies of Photoinhibition, Cold Acclimation and Freezing Stress [and Discussion]. Philosoph. Trans. Royal Soc. London B: Biol. Sci. 1989, 323, 281-293. [CrossRef]

85. Duan, M.; Feng, H.-L.; Wang, L.-Y.; Li, D.; Meng, Q.-W. Overexpression of thylakoidal ascorbate peroxidase shows enhanced resistance to chilling stress in tomato. J. Plant Physiol. 2012, 169, 867-877. [CrossRef] [PubMed]

86. Hu, Y.; Wu, Q.; Sprague, S.A.; Park, J.; Oh, M.; Rajashekar, C.B.; Koiwa, H.; Nakata, P.A.; Cheng, N.; Hirschi, K.D.; et al. Tomato expressing Arabidopsis glutaredoxin gene AtGRXS17 confers tolerance to chilling stress via modulating cold responsive components. Horticul. Res. 2015, 2, 15051. [CrossRef] [PubMed]

87. Moon, J.C.; Lee, S.; Shin, S.Y.; Chae, H.B.; Jung, Y.J.; Jung, H.S.; Lee, K.O.; Lee, J.R.; Lee, S.Y. Overexpression of Arabidopsis NADPH-dependent thioredoxin reductase C (AtNTRC) confers freezing and cold shock tolerance to plants. Biochem. Biophys. Res. Commun. 2015, 463, 1225-1229. [CrossRef] [PubMed]

88. Maruta, T.; Tanouchi, A.; Tamoi, M.; Yabuta, Y.; Yoshimura, K.; Ishikawa, T.; Shigeoka, S. Arabidopsis Chloroplastic Ascorbate Peroxidase Isoenzymes Play a Dual Role in Photoprotection and Gene Regulation under Photooxidative Stress. Plant Cell Physiol. 2010, 51, 190-200. [CrossRef] [PubMed]

89. Cheng, N.-H.; Liu, J.-Z.; Liu, X.; Wu, Q.; Thompson, S.M.; Lin, J.; Chang, J.; Whitham, S.A.; Park, S.; Cohen, J.D.; et al. Arabidopsis monothiol glutaredoxin, AtGRXS17, is critical for temperature-dependent postembryonic growth and development via modulating auxin response. J. Biol. Chem. 2011, 286, 20398-20406. [CrossRef] [PubMed]

90. Baier, M.; Bittner, A.; Prescher, A.; van Buer, J. Preparing plants for improved cold tolerance by priming. Plant Cell Environ. 2018. [CrossRef] [PubMed]

91. Dietz, K.-J. Subcellular metabolomics: The choice of method depends on the aim of the study. J. Exp. Bot. 2017, 68, 5695-5698. [CrossRef] [PubMed]

92. Hoermiller, I.I.; Naegele, T.; Augustin, H.; Stutz, S.; Weckwerth, W.; Heyer, A.G. Subcellular reprogramming of metabolism during cold acclimation in Arabidopsis thaliana. Plant Cell Environ. 2017, 40, 602-610. [CrossRef] [PubMed]

93. Meyer, A.J.; Brach, T.; Marty, L.; Kreye, S.; Rouhier, N.; Jacquot, J.-P.; Hell, R. Redox-sensitive GFP in Arabidopsis thaliana is a quantitative biosensor for the redox potential of the cellular glutathione redox buffer. Plant J. 2007, 52, 973-986. [CrossRef] [PubMed]

94. Polle, A. Dissecting the Superoxide Dismutase-Ascorbate-Glutathione-Pathway in Chloroplasts by Metabolic Modeling. Computer Simulations as a Step towards Flux Analysis. Plant Physiol. 2001, 126, 445-462. [CrossRef] [PubMed]

(c) 2018 by the authors. Licensee MDPI, Basel, Switzerland. This article is an open access article distributed under the terms and conditions of the Creative Commons Attribution (CC BY) license (http:/ / creativecommons.org/licenses/by/4.0/). 